\title{
MIKROZONASI KAWASAN RAWAN BENCANA GEMPABUMI DENGAN STUDI PEAK GROUND ACCELERATION MENGGUNAKAN METODE BOORE ATKINSON DAN DATA MIKROTREMOR DI DAERAH KUPANG
}

\author{
Rachmat Jariah Jamal $^{1 *}$, Lantu ${ }^{1}$, Sabrianto Aswad ${ }^{1}$, Cecep Sulaiman ${ }^{2}$ \\ ${ }^{\text {I}}$ Program Studi Geofisika, FMIPA Universitas Hasanuddin, Makassar \\ ${ }^{2}$ Pusat Vulkanologi dan Mitigasi Bencana Geologi, Badan Geologi, Bandung \\ *Peulis koresponden. Alamat email: jajarachm@gmail.com
}

\begin{abstract}
Abstrak
Letak geografis Indonesia yang berada pada pertemuan tiga lempeng tektonik utama; Lempeng Indo-Australia, Lempeng Eurasia dan Lempeng Pasifik, menjadikan Indonesia sebagai kawasan rawan gempabumi. Berdasarkan data yang dirilis oleh Direktorat Vulkanologi dan Mitigasi Bencana Geologi (DVMBG) terdapat 28 wilayah rawan gempa dan tsunami termasuk Kupang. Kupang terletak di zona busur sangat aktif dan tepian benua aktif. Kegiatan tektonik yang berlangsung saat ini dicirikan dengan kejadian gempa tektonik yang melanda daerah pedalaman, akibat dari aktifnya sesar-sesar yang terdapat di perbukitan sekitar Kota Kupang. Salah satu upaya mitigasi yang dilakukan adalah pengukuran mikrotremor menggunakan metode HVSR (Horizontal to Vertical Spectral Ratio) untuk mengetahui nilai frekuensi dominan yang akan menjadi penentu tingkat kerawanan bencana gempabumi. Nilai frekuensi dominan akan menghitung nilai kecepatan gelombang S hingga kedalaman 30 meter (Vs30) yang selanjtnya digunakan untuk menentukan nilai PGA dan amplifikasi. Hasil analisis data menunjukkan bahwa nilai periode dominan berada pada rentang 0.1-0.97 sekon, nilai PGA antara 92.87-142.84 gal dan nilai amplifikasi adalah 0.99-4.38 dan 2.12-9.43 kali. Maka dapat disimpulkan bahwa daerah penelitian termasuk kategori rawan bencana gempabumi terutama pada bagian tenggara.
\end{abstract}

Kata Kunci : Amplifikasi, Mikrotremor, Periode Dominan, PGA

\begin{abstract}
Geographically, Indonesia located at the meeting of three major tectonic plates; Indo-Australian Plate, Eurasian Plate, and Pacific Plate, that make Indonesia as earthquake-prone area. Based on data released by the Directorate of Volcanology and Geological Hazard Mitigation (DVMBG), there are 28 earthquake and tsunami prone areas including Kupang that the area located in the very active arc zone and the edge of the active continent. The tectonic activity that is currently taking place is characterized by the tectonic earthquake that attacks to countryside areas, resulting from the active fault-faults found in the hills around the area. One of the mitigation efforts is microtremor measurement using HVSR (Horizontal to Vertical Spectral Ratio) method to find out the dominant frequency for determination of the magnitude of the earthquake. The predominant frequency value will determine the Shear wave velocity up to 30 meters (Vs30) which are further used for the PGA and amplification values. The result of data analysis shows that the dominant period value is in the range 0.1-0.97 second, PGA value between 92.87-142.84 gal and the amplification value is 0.99-4.38 and 2.12-9.43 times. The conclusion, the area is categorized as earthquake-prone, especially in the southeast region.
\end{abstract}

Keywords: Amplification, Microtremor, Dominant Period, PGA 


\section{Pendahuluan}

Kepulauan Indonesia terletak pada pertemuan tiga lempeng tektonik utama, yaitu lempeng Indo-Australia di bagian Selatan, lempeng Eurasia di bagian Utara, dan lempeng Pasifik di bagian Timur. Letak geografis tersebut menyebabkan Indonesia menjadi kawasan yang rawan terhadap bencana besar, terutama bencana geologis. Catatan dari Direktoran Vulkanologi dan Mitigasi Bencana Geologi (DVMBG) Departemen Energi dan Sumber Daya Mineral menunjukkan bahwa terdapat 28 wilayah yang dinyatakan rawan gempa dan tsunami. Kupang sebagai salah satu daerah yang berada di NTT juga dapat merasakan efek dari kejadian gempabumi yang terjadi di sekitarnya.

Secara garis besar tingkat kerusakan yang terjadi akibat gempabumi bergantung dari kekuatan dan kualitas bangunan, kondisi geologi dan geotektonik serta percepatan tanah maksimum daerah lokasi gempabumi terjadi (Edwisa \& Novita, 2008 dalam Susanto, 2011). Oleh karena itu mikrozonasi daerah rawan bencana gempabumi dapat dimanfaatkan untuk meminimalisir terjadinya kerusakan di daerah tersebut.

\section{Kondisi Geologi Daerah Penelitian}

Menurut Rosidi, dan Tjokrosapoetro (1979), proses tektonik akibat dari penunjaman yang terjadi dari pergerakan Lempeng Indo Australia, posisi Laut Timor adalah jalur subduksi ke arah utara, mengakibatkan Kepulauan Timor, sebagai lempeng benua, mengalami pengangkatan, perlipatan, dan pensesaran. Kegiatan tektonik yang berlangsung saat ini dicirikan dengan kejadian gempa tektonik yang melanda daerah pedalaman, akibat dari aktifnya sesar-sesar yang terdapat di perbukitan sekitar Kota Kupang. Lastiadi, 2003 dalam Darmawan, 2010).

a. Kompleks Bobonaro, terdiri atas dua bagian. Bagian pertama adalah batu lempung bersisik dan bongkah-bongkah rijang, dan yang kedua adalah batuan ultra basa dan batu gamping dengan berbagai ukuran yang tertanam pada masa batu lempung.

b. Formasi Noele, terdiri dari napal berselingan dengan batu pasir, konglomerat, dan tufa.

c. Satuan Batu Gamping Koral, berupa batu gamping koral yang bagian bawahnya terdapat batu gamping klastik

d. Aluvium, berupa endapan sungai dan endapan pantai

Berdasarkan morfologi dan batuan penyusunnya, disusun Satuan Geologi Lingkungan (SGL), yaitu Pedataran aluvium, Pedataran berombak lempung hitam dan terarosa, Perbukitan rendah batu gamping, Perbukitan kars, dan Perbukitan napal dan batu lempung (Lastiadi, 2003 dalam Darmawan, 2010).

\section{Mikrotremor}

Mikrotremor diartikan sebagai getaran harmonik alami tanah yang terjadi secara terus menerus, terjebak dilapisan sedimen permukaan, terpantulkan oleh adanya bidang batas lapisan dengan frekuensi yang tetap, disebabkan oleh getaran mikro di bawah permukaaan tanah dan kegiatan alam lainnya. Penelitian mikrotremor dapat mengetahui karakteristik lapisan tanah berdasarkan parameter periode dominannya dan faktor penguatan gelombangnya (amplifikasi). 


\section{Mikrozonasi}

Mikrozonasi mikrotremor adalah suatu proses pembagian area berdasarkan parameter tertentu memiliki karakteristik yang dipertimbangkan antara lain adalah getaran tanah, faktor penguatan (amplifikasi) dan periode dominan.

Dalam mikrozonasi mikrotremor terdapat beberapa metode yang kerap digunakan, antara lain (Arifin, 2013):

a. Analisis HVSR (Horizontal - Vertical Spectral Ratio). Metode membandingkan spektrum komponen horizontal terhadap komponen vertikal dari gelombang mikrotremor.

b. Analisis Frekuensi Dominan dan Periode Dominan. Frekuensi dominan adalah nilai frekuensi yang kerap muncul sehingga diakui sebagai nilai frekuensi dari lapisan batuan di wilayah tersebut sehingga nilai frekuensi dapat menunjukkan jenis dan karakterisktik batuan tersebut. Nilai periode dominan juga mengindikasikan karakter lapisan batuan.

\section{Transformasi Fourier}

Transformasi Fourier adalah metoda untuk mengubah data seismik dalam domain waktu menjadi domain frekuensi. Fourier didefenisikan sebagai (Riyanto, 2009):

$$
\begin{aligned}
x(f) & =\int_{-\infty}^{+\infty} x(t) e^{-j 2 \pi} d \\
& =\int_{-\infty}^{\infty} x(t) \cos (2 \pi f t) d \\
& =-j \int_{-\infty}^{\infty} x(t) \sin (2 \pi f t) d t
\end{aligned}
$$

Dimana:

$x(t) \quad=$ sinyal dalam domain waktu,

$e^{-j 2 \pi f}=$ fungsi kernel,

$X(f) \quad=$ fungsi dalam domain frekuensi,

$f \quad=$ frekuensi

\section{Penghalusan Data}

Penghalusan data bertujuan untuk memperhalus data untuk meminimalisasi keberadaan noise dengan cara dilakukan filterisasi menggunakan fast fourier transformation. Penghalusan data ini menggunakan prinsip Konno dan Ohmachi, yakni menggunakan bandwith konstan pada skala logarithmic

Kecepatan Gelombang $S$ Hingga Kedalaman 30 Meter $\left(V_{30}\right)$

Kecepatan gelombang $\mathrm{S}$ merupakan parameter penting untuk mengevaluasi perilaku dinamis dari tanah di bawah permukaan dangkal. Dengan demikian karakterisasi situs dalam menghitung bahaya seismik biasanya didasarkan pada nilai kecepatan gelombang $\mathrm{S}$ dekat dengan permukaan. Kecepatan rata-rata gelombang $\mathrm{S}$ dihitung dengan membagi 30 meter dengan waktu tempuh dari permukaan ke kedalaman 30 meter, seperti pada persamaan 2.14 (Wibowo, 2015) :

$$
\mathrm{VS}_{30}=\frac{3}{\sum_{\mathrm{i}= \pm}^{N} \frac{n_{l}}{V_{\mathrm{L}}}}
$$

$h_{i}$ adalah ketebalan lapisan dan $V_{i}$ kecepatan gelombang $\mathrm{S}$ pada layer $\mathrm{N}$. $\mathrm{N}$ adalah lapisan kesekian yang ada pada kedalaman 30 meter.

\section{Inversi Kurva HVSR}

Inversi kurva HVSR dilakukan dengan menggunakan software ModelHVSR yang dikembangkan oleh Herak (2008), dengan pendekatan kurva HVSR berbasis gelombang badan untuk mendapatkan parameter kecepatan gelombang $\mathrm{S}(\mathrm{Vs}) \mathrm{di}$ titik pengukuran mikrotremor (Mufida, 2013). Inversi HVSR adalah modul yang menginversi HVSR observasi untuk menentukan model tanah yang terbaik. 
Algoritma ini didasarkan pada kombinasi sederhana dan panduan Monter Carlo pada pencarian model ruang yang meminimalkan fungsi ketidakcocokan.

\section{Site class dan Amplifikasi}

Batas-batas kecepatan dari klasifikasi situs NEHRP dimanfaatkan untuk memperkirakan kemampuan tanah dangkal dan batu, untuk menjelaskan lokal gerakan tanah yang kuat. Amplifikasi terjadi akibat adanya perbedaan yang signifikan antar lapisan, dengan kata lain gelombang seismik akan mengalami perbesaran, jika merambat pada suatu medium ke medium lain yang lebih lunak dibandingkan dengan medium awal yang dilaluinya.

Peak Ground Acceleration (Percepatan Tanah Maksimum)

PGA dinyatakan dalam satuan percepatan gravitasi (Gravitational Acceleration = gal) atau $\mathrm{cm} / \mathrm{s}^{2}$. Nilai percepatan tanah maksimum yang dihasilkan menunjukkan tingkat resiko bencana yang terjadi. Pengukuran Peak Ground Acceleration pada penelitian ini menggunakan metode BooreAtkinson berdasarkan hasil penelitiannya tentang Ground-Motion Prediction Equation (GMPEs).

\section{Interpolasi Kriging}

Secara umum, kriging merupakan suatu metode untuk menganalisis data geostatistik untuk menginterpolasi suatu nilai berdasarkan data. Metode kriging adalah metode interpolasi yang berbasis geostatistik (Widjajanti dan Sutanta, 2006).

\section{Metode Skoring dan Pembobotan}

Metode skoring adalah suatu metode pemberian skor atau nilai terhadap masingmasing value parameter untuk tingkat keamampuannya. Penilaian ini berdasarkan kriteria yang telah ditentukan. Sedangkan metode pembobotan atau disebut juga weighting adalah suatu metode yang digunakan apabila setiap karakter memiliki peranan berbeda atau jika memiliki beberapa paameter untuk menentukan kemampuan lahan atau sejenisnya (Sholahuddin, 2014).

\section{Data dan Metode}

Data pengukuran yang digunakan merupakan data sekunder dari Pusat Vulkanologi dan Mitigasi Bencana Gelogi sejumlah 54 titik. Data diolah untuk mendapatkan kurva HVSR yang nantinya akan diinversi untuk mendapatkan nilai vs30.

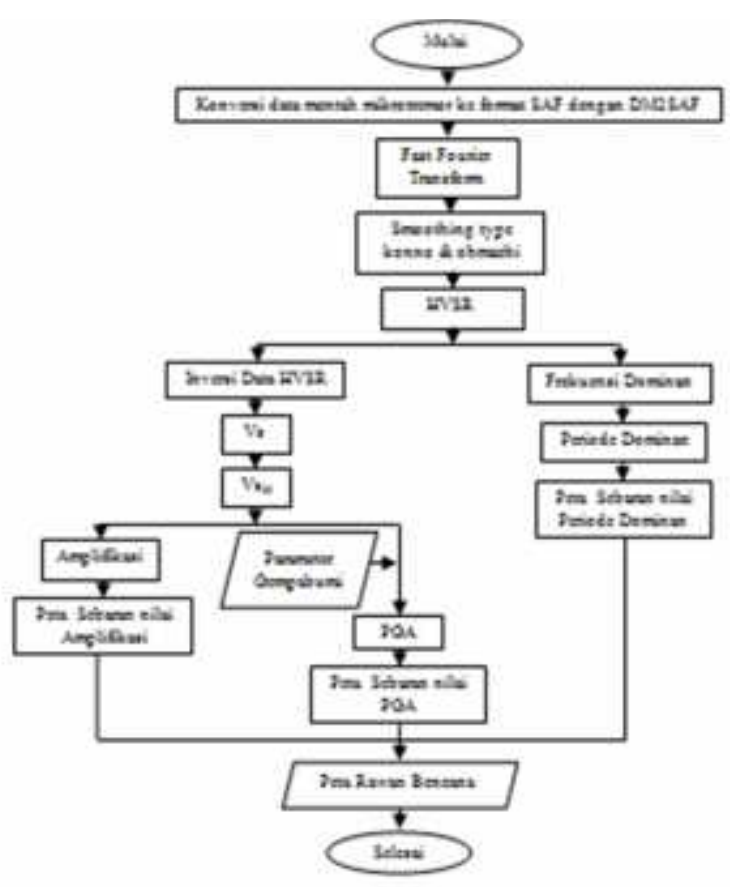

Gambar 1. Diagram Alir Penelitian

\section{HASIL DAN PEMBAHASAN}

Sinyal mikrotremor yang diperoleh selanjutnya dilakukan picking untuk 
menemukan sinyak yang stationer berdasarkan fungsi waktu. Hasil picking akan terlihat seperti pada gambar 2. Hasil picking tersebut selanjutnya diolah dengan metode Nakamura atau HVSR untuk mengetahui nilai frekuensi dominan dan faktor amplifikasinya.

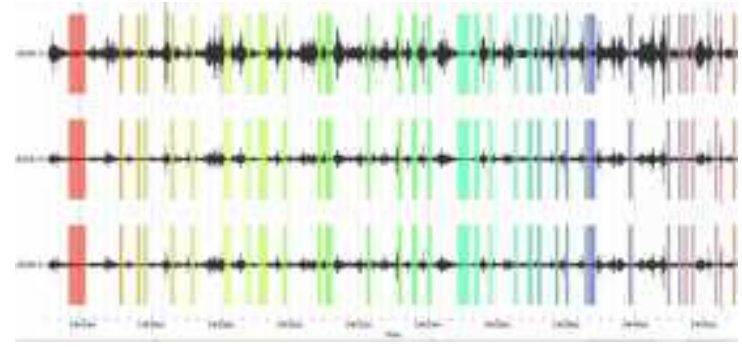

Gambar 2. Picking data mikrotremor titik k006.

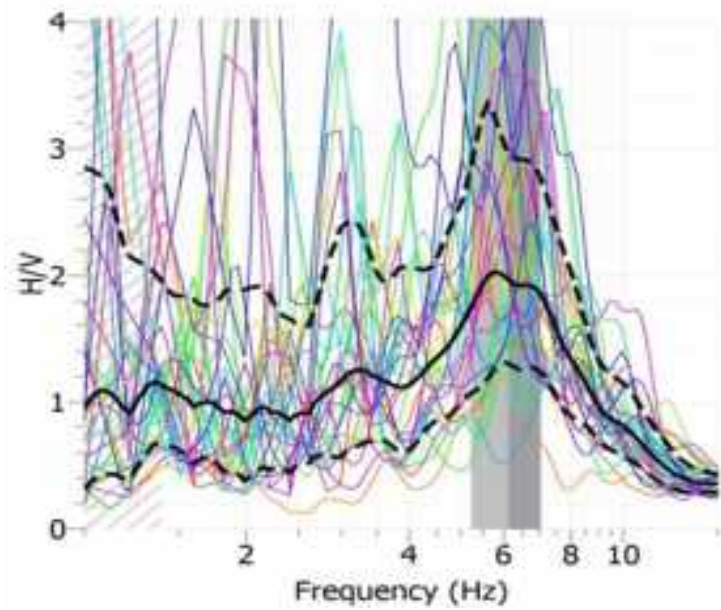

Gambar 3. Hasil olahan HVSR setelah dilakukan fft dan smoothing pada software Geopsy di titik k006.

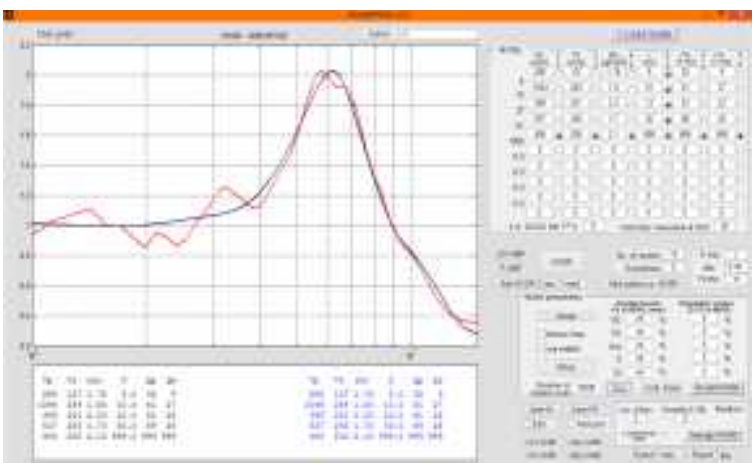

Gambar 4. Pemodelan kurva HVSR menggunakan software modelHVSR Herak pada titik k006.

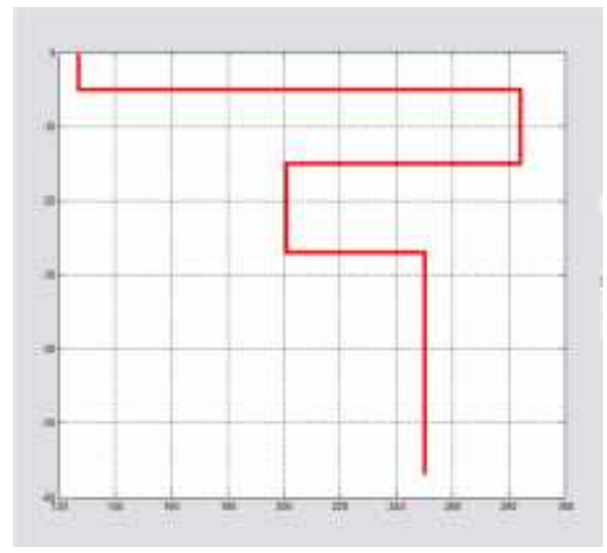

Gambar 5. Kurva nilai kecepatan gelombang $s$ terhadap kedalaman hasil proses inversi kurva HVSR titik k006.

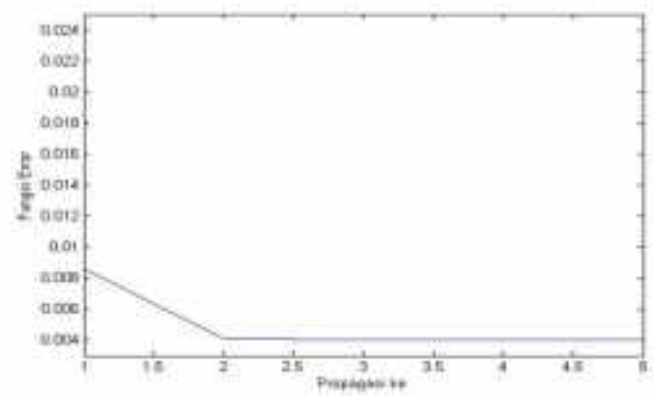

Gambar 6. Nilai Error dari hasil Inversi di titik k006.

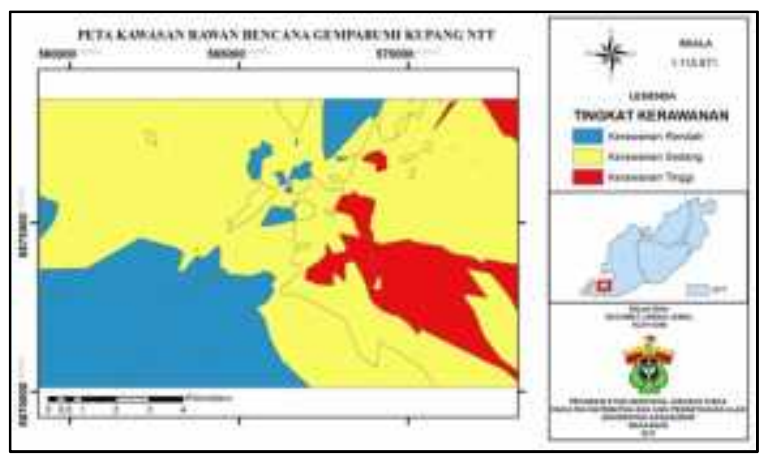

Gambar 7. Peta kawasan rawan gempa bumi daerah Kupang.

Data hasil pengukuran diolah menggunakan software Geopsy untuk mendapatkan spektrum HVSR seperti pada Gambar 3. Terlebih dahulu dilakukan windowing secara manual seperti yang terlihat pada Gambar 2 . Kemudian dilakukan proses smoothing type Konno dan Ohmachi sesuai dengan ketentuan di SESAME. 
Hasil analisis nilai frekuensi dominan di daerah penelitian menghasilkan nilai dengan rentang 1,02353 - 9,95166 Hz. Nilai frekuensi dominan tersebut kemudian digunakan untuk menghitung nilai periode dominan. Besarnya nilai periode dominan tanah menunjukkan tingkat kerentanan masing-masing pengukuran. Semakin besar nilai periode dominan tanah disuatu lokasi maka semakin rentan lokasi tersebut dari goncangan gempabumi. Nilai periode dominan yang tersebar di daerah kupang seperti yang terlihat pada gambar 4.7 berada pada rentang $0,100485748-0,977010933$.

Tahap selanjutnya adalah penentuan nilai Vs30. Untuk melakukan inversi HVSR, terlebih dahulu dilakukan input model awal yang terdiri atas 6 parameter $(\mathrm{Vp}, \mathrm{VS}, \rho, \mathrm{h}$, Qp dan Qs) dan selanjutnya dimasukkan nilai HVSR observasi. Software akan melakukan inversi sehingga model yang dimasukkan akan mendekati nilai dari data hasil pengukuran seperti yang terlihat pada Gambar 4. Parameter Vs30 seringkali digunakan dalam perhitungan GMPEs sebagai indikasi bahaya gempabumi. Nilai ini mewakili kecepatan rata-rata gelombang s sampai kedalaman 30 meter. Dalam penelitian ini nilai $\mathrm{Vs}$ ditentukan dengan menginversi kurva HVSR menggunakan software ModelHVSR yang kemudian dapat dihitung nilai Vs30 nya. Nilai vs30 daerah kupang berada pada rentang 67,46111 $387,4147 \mathrm{~m} / \mathrm{s}$.

Selanjutnya adalah penghitungan nilai Peak Ground Acceleration (PGA) yang merupakan salah satu parameter penentu dalam pembuatan peta rawan bencana. PGA adalah nilai percepatan gelombang pada lapisan batuan yang timbul akibat adanya gempabumi. Setiap parameter masukan gempabumi yang digunakan akan menghasilkan nilai PGA yang berbeda, bahkan nilai PGA akan berbeda pada lokasi titik yang berbeda meskipun parameter masukannya berupa gempa yang sama. Pada gambar 4.9 menunjukkan persebaran nilai PGA di dearah penelitian dengan rentang nilai 92,8783037 - 142,841944 gal.

Nilai lainnya yang dihitung adalah nilai amplifikasi yang merupakan parameter terjadinya penguatan gelombang pada lapisan sedimen dengan frekuensi resonasi tertentu. Persebaran amplifikasi pada daerah penelitian yaitu: nilai amplifikasi terendah dengan nilai 2.12 kali (+0.166) dan 0.99 kali (-0.166), sedangkan nilai amplifikasi tertinggi dengan nilai 9.43 kali $(+0.166)$ dan 4.39 kali (-0.166).

Dengan mengacu pada tiga parameter tersebut diatas yaitu nilai periode dominan, PGA dan amplifikasi dapat dibuat peta kawasan rawan bencana gempabumi di daerah penelitian dengan menggunakan metode skoring dan pembobotan berdasarkan pengaruhnya terhadap gempabumi. kemudian dari hasil skoring dan pembobotan tersebut dibuat peta kawasan rawan bencana gempabumi seperti yang terlihat pada gambar 7. Pada gambar tersebut terlihat bahwa daerah yang lebih rawan bencana gempabumi berada dibagian tengah mengarah mengarah ke tenggara di wilayah kec. Maulafa dan sebelah barat laut di wilayah kec. Kelapa Lima dibandingkan daerah di sebelah barat daya dan utara.

\section{KESIMPULAN}

Berdasarkan hasil penelitian yang telah dilakukan maka dapat disimpulkan sebagai berikut:

1. Nilai frekuensi dominan untuk daerah penelitian berada pada rentang 1,023539,95166 Hz. Hal tersebut menunjukkan 
bahwa daerah penilitian memiliki nilai frekuensi dominan yang rendah. Adapun nilai kecepatan gelombang $\mathrm{S}$ pada kedalaman 30 meter berkisar 67,46111 $387,4147 \mathrm{~m} / \mathrm{s}$.

2. Nilai PGA dan periode dominan di daerah penelitian berada pada rentang yang termasuk dalam kategori rawan terhadap bencana gempabumi. Berdasarkan nilai PGA, daerah penelitian terdapat wilayah dengan kategori resiko sedang II, Resiko Sedang III, dan Resiko Besar I atau dengan skala intensitas MMI VII sampai IX. Berdasarkan nilai periode dominan, daerah penelitian terdapat wilayah dengan karakter sedang, lunak, dan sangat lunak yang akan berpangaruh jika terjadi gempabumi.

Nilai amplifikasi daerah penelitian berada pada rentang 0,99-4,38 dan 2,12-9,42, yang berarti jika terjadi gempabumi maka gelombang gempa akan mengalami perbesaran sebanyak 0,99 sampai 9,42 kali.

3. Berdasarkan peta tingkat kerawanan bencana gempabumi daerah penelitian dari hasil gabungan tiga nilai parameter, daerah yang paling rawan terkena bencana adalah wilayah kecamatan Maulafa dan yang paling rendah di wilayah kecamatan Alak. Meskipun hampir secara keseluruhan termasuk dalam kategori rentan terjadi bencana gempabumi.

\section{UCAPAN TERIMA KASIH}

Terima kasih kepada Bapak Cecep Sulaiman selaku pembimbing penulis serta pihakpihak yang membantu penulis selama Tugas
Akhir di Pusat Vulkanologi dan Mitigasi Bencana Gempabumi.

\section{DAFTAR PUSTAKA}

Arifin, S.S., Mulyatno, B.S., Marjiyono, \& Setianegara, R. 2013. Penetuan Zona Rawan Guncangan Bencana Gempa Bumi Berdasarkan Analisis Nilai Amplifikasi Hvsr Mikrotremor dan Analisis Periode Dominan Daerah Liwa dan Sekitarnya. Jurnal Geofisika Eksplorasi Vol2/No.1

Darmawan, A., \& Lastiadi, H.A. 2010. Geologi Lingkungan dan Fenomena Kars Sebagai Arahan Pengembangan Wilayah Perkotaan Kupang, Nusa Tenggara Timur. Jurnal Lingkungan dan Bencana Geologi, Vol 1 No. 1

Riyanto, S., Purwanto, A., \& Supardi. 2009. Algoritma Fast Fourier Transform (FFT) Decimation In Time (DIT) Dengan Resolusi 1/10 Hertz. Prosiding seminar nasional penelitian, pendidikan, dan penerapan MIPA, Fakultas MIPA, Universitas Negeri Yogyakarta.

Rosidi H.M.D, dan Tjokrosapoetro, S. 1996. Peta Geologi Lembar KupangAtambua, Timor, skala 1:250.000. Pusat Penelitian dan Pengembangan Geologi. Bandung.

Mufida, A., Santosa, B.J. , \& Warnana, D.D. 2013. Profiling Kecepatan gelombang Geser (Vs) Surabaya Berdasarkan Pengolahan Data Mikrotremor. Jurnal Sains dan Seni POMITS Vol. 2, No. 2, (2013) 2337-3520 (2301-928X Print).

Sholahuddin D. S, M. 2014. SIG untuk Memetakan Daerah Banjir dengan Metode Skoring dan Pembobotan (Studi Kasus Kabupaten Jepara). Jurnal. Sistem informasi. Fasilkom, Udinus.

Susanto, A. 2011. Perhitungan Percepatan Tanah Maksimum Berdasarkan Data 
Gempa Bumi Di Daerah Istimewa Yogyakarta (hlm.1\&2). Semarang: Universitas Negeri Semarang.

Wibowo, B.A., Rudiyanto, A., Ibrahim, G., Ali, Y.H., Perreira, A.T.F., \& Trismahargyono. 2015. Studi Pendahuluan Mikrozonasi Kota Tangerang Selatan Melalui Analisi Nilali Vs-30 dan Periode Dominan. Jurnal Meteorologi Klimatologi dan Geofisika (Edisi Wisuda STMKG), Vol. 2, No. 3, Oktober 2015. 